\title{
Techniques for Interim Rrestorations in Fixed Partial Denture Prosthesis - A Review
}

Praveen B ${ }^{1}$ Prasanna B.G ${ }^{2}$, Sri Harsha ${ }^{3}$, N.Chandana ${ }^{4}$

${ }^{1,2,3}$ Reader, ${ }^{4}$ Post Graduate Student, Department of Prosthodontics, College of Dental Sciences, Davanagere.

\section{Abstract:}

It is important for the tooth or teeth to be protected and that the patients be kept comfortable while a permanent restoration is being fabricated. By successful management of this phase, the dentist can gain patients confidence and favorably influence the ultimate success of the final restoration. Therefore costly chair side time must not be wasted but the dentist must produce an acceptable restoration. This paper reviews the techniques for custom provisional restorations.

Keywords: Aesthetics; Custom made restoration; External surface form; Interim restoration; Preformed matrix.

\section{Introduction}

Interim restoration is a fixed or removable prosthesis, designed to enhance esthetics, stabilization and/ or function for a limited period of time, after which it is to be replaced by a definitive prosthesis ${ }^{1,2}$. Provisional restorations play a key role in gaining the patients confidence and also save the valuable clinical chair side time. They also provide psychological support till the final restoration is fabricated ${ }^{3}$.

\section{Requirements of Provisionals ${ }^{1,2}$ :}

\section{Biologic Requirements}

Pulp protection

Periodontal Health

Occlusal harmony

Positional Stability

Protection of margin

\section{Mechanical Requirements}

Adequate Compressive/Flexural Strength

Good Retention \& Stability

\section{Esthetic Requirements}

Color stability, Easily contourable, Translucency

\section{Rationale for provisional restoration ${ }^{3}$}

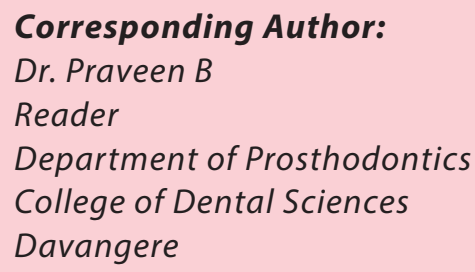

1. To immediately replace missing teeth.

2. To prevent migration of abutments.

3. To improve esthetics.

4. To aid in developing occlusal scheme before final prosthesis is made.

5. To evaluate vertical dimension, phonetics and masticatory function.

\section{Provisional luting materials should posses:}

1. Tooth adhesion to resist bacterial and molecular penetration.

2. Sufficient working time to place the restoration.

3. It must be fluid enough to allow complete seating of the restoration.

4. It must quickly form a hard mass strong enough to resist functional forces.

The most important function of these materials is to provide an adequate seal between the provisional restoration and prepared tooth. The most common luting materials used for interim purposes are Calcium hydroxide, Zinc oxide eugenol, Non eugenol materials. As eugenol interferes with the acrylic resin polymerization and hardening process, eugenol free provisional luting materials have gained popularity.

\section{Steps in fabrication of interim restorations ${ }^{1,2,3}$}

1. Diagnostic wax up on study models.

2. Fabrication of matrix/external surface form.

3. Contouring the tissue surface form of provisional restoration.

4. Cementation and evaluation of restoration 


\section{Diagnostic wax up on the study models (Fig.1)}

It is to be done to change or correcting occlusal abnormalities.

To restore/alter the V.D.O.

It also help to fabricate the customized matrix form. The diagnostic wax up has to be done and all occlusal interferences should be eliminated and then utilized for further procedures.

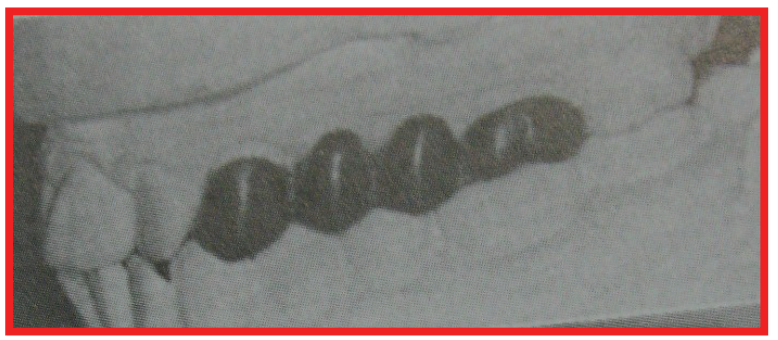

Fig.1 : Diagnostic wax up on the study models

\section{External surface form}

1. Preformed matrix.

2. Fabrication from Diagnostic wax up.

\section{Preformed matrix are of different types:}

Polycarbonate crowns.(Fig.4)

Cellulose acetate crown forms.

Metallic crown/shells.

\section{Aluminum Shells/Anatomic crowns (Fig.2)}

Stainless steel Crowns

Nickel-Chromium crowns (Fig.3)

Tin-Silver \& Tin-Bismuth Crowns

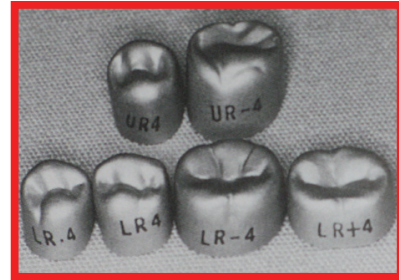

Fig.2 : Aluminium anatomic crowns available in a variety of sizes and shape. The manufacturers has produced two maxillary and four mandibular shape for the left and right side of the mouth, each in six sizes².

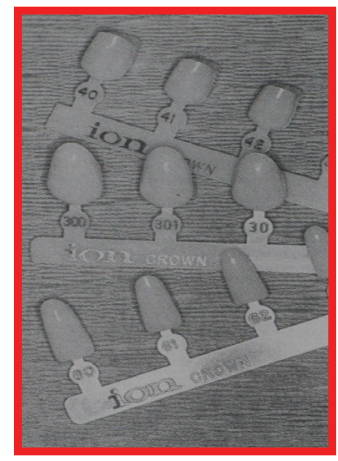

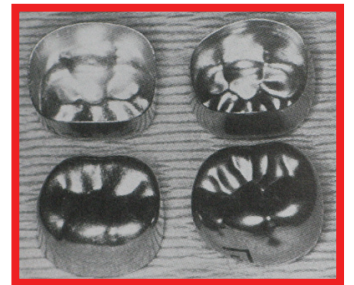

Fig.3 : Ni-Cr anatomic crows. These are available in an array of sizes and shapes, including once for the primary teeth with straight and contour axial surfaces².
Fig. 4 : Polycarbonate crowns. Available in maxillary and mandibular incisor, canine and premolar shapes ${ }^{2}$

\section{Customized Surface forms}

It can be done by using different materials:

Alginate

The putty material

Vacuum Adopted Thermoplastic sheets.

Wax

Table 1 : Characteristics of resins used for provisional restorations ${ }^{2,8}$

\begin{tabular}{|c|c|c|c|c|}
\hline Type & Brand & Manufacturer & Advantages & Disadvantages \\
\hline $\begin{array}{l}\text { Poly(methyl } \\
\text { methacrylate) }\end{array}$ & $\begin{array}{c}\text { Alike Cf \& } \\
\text { Br Resin } \\
\text { Duralay Jet }\end{array}$ & $\begin{array}{c}\text { GC America LD } \\
\text { Caulk Reliance } \\
\text { Dental Lang } \\
\text { Dental }\end{array}$ & $\begin{array}{c}\text { Good margin fit } \\
\text { Good transverse strength } \\
\text { Good polish ability } \\
\text { Durability }\end{array}$ & $\begin{array}{l}\text { High exothermic heat increase } \\
\text { Low abrasion resistance } \\
\text { Free monomer toxic to pulp } \\
\text { High volumetric shrinkage }\end{array}$ \\
\hline $\begin{array}{l}\text { Poly(ethyl } \\
\text { methacrylate) }\end{array}$ & Snap & $\begin{array}{c}\text { Parkeli } \\
\text { Biomaterials }\end{array}$ & $\begin{array}{c}\text { Good polish ability } \\
\text { Minimal exothermic heat increase } \\
\text { Good strain resistance } \\
\text { Low shrinkage }\end{array}$ & $\begin{array}{l}\text { Surface hardness } \\
\text { Transverse strength } \\
\text { Durability } \\
\text { Fracture toughness }\end{array}$ \\
\hline $\begin{array}{l}\text { Poly(vinylethyl } \\
\text { methacrylate) }\end{array}$ & Trim & Harry Bosworth & $\begin{array}{c}\text { Good polish ability } \\
\text { Minimal exothermic heat increase } \\
\text { Good strain resistance } \\
\text { Good abrasion resistance } \\
\text { Flexibility }\end{array}$ & $\begin{array}{c}\text { Surface hardness } \\
\text { Transverse strength } \\
\text { Durability } \\
\text { Fracture toughness }\end{array}$ \\
\hline $\begin{array}{l}\text { Bis-acryl } \\
\text { composite }\end{array}$ & Protemp II & ESPE-Premier & $\begin{array}{c}\text { Good marginal fit } \\
\text { Low exothermic heat increase } \\
\text { Good abrasion resistance } \\
\text { Good transverse strength } \\
\text { Low shrinkage }\end{array}$ & $\begin{array}{c}\text { Surface hardness } \\
\text { Less stain resistance } \\
\text { Limited shade selection } \\
\text { Limited polish ability } \\
\text { Brittle }\end{array}$ \\
\hline $\begin{array}{l}\text { VLC urethane } \\
\text { di } \\
\text { methacrylate }\end{array}$ & Triad & Dentsply York & $\begin{array}{c}\text { High Surface hardness } \\
\text { Good transverse strength } \\
\text { Good abrasion resistance } \\
\text { Controllable working time } \\
\text { Color stability }\end{array}$ & $\begin{array}{c}\text { Marginal fit } \\
\text { Less strain resistance } \\
\text { Limited shade selection } \\
\text { Expensive } \\
\text { Brittle }\end{array}$ \\
\hline
\end{tabular}




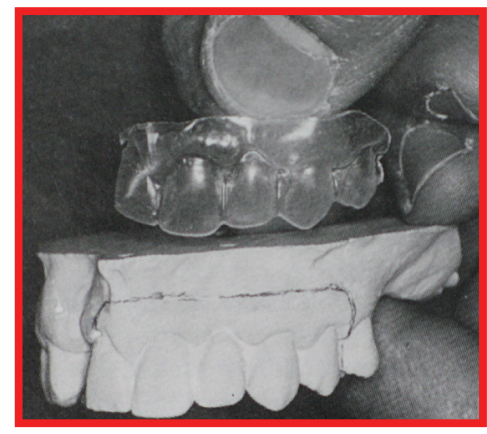

Fig. 5 : External surface form removed ${ }^{2}$.

\section{Contouring of the tissue surface form ${ }^{2,3}$}

- Direct Technique

- Indirect Technique

- Hybrid Technique

\section{Direct technique ${ }^{3}$}

The direct technique is performed by making the provisional directly in the mouth. It is usually chosen when a single unit or small span bridge is being fabricated. It is cost-effective to fabricate the provisional directly and requires less chair time. For instance, choosing a polycarbonate crown form for an anterior tooth and relining it with acrylic will save time since it is not necessary to take impressions, pour models or make a template. There are numerous ways to fabricate a provisional utilizing the direct technique. The most common ones are the polycarbonate crown forms, alginate impressions, preformed crowns, clear matrices and baseplate wax.

\section{Indirect technique}

After tooth preparation the impression of the arch is made and poured with the quick set stone or plaster and the provisional restoration is fabricated on the cast so it is called indirect technique.

\section{Putty index technique / shell fabricated provisional restoration $^{8}$ :}

-Diagnostic wax up is done

-Putty index is made from diagnostic wax up.

-Trimmed acrylic shells are oriented in the putty index.

-Auto polymerizing resin is filled in the putty index.

-The index is stabilized on the prepared sectional cast.

-Provisional restoration is finished.

\section{Hybrid technique or indirect-direct technique}

The diagnostic tooth preparation is carried on models and slightly the tooth is under prepared and these are used as tissue surface forms. The provisionals are fabricated by indirect technique and when the preparation is completed in the clinic the provisionals are relined by self curing resin chair side.

\section{Provisional restorations in different clinical conditions for anterior teeth: Single crown ${ }^{4}$}

-If tooth has normal contours, contacts, then same tooth form is retained by custom made matrix.

-If tooth is grossly destructed then the diagnostic wax up has to be done followed by matrix formation or preformed matrix can be used.

-After tooth preparation, the exposed tooth surface is covered with a layer of petroleum jelly.

-Self curing resin is mixed and loaded into the matrix.

Once the mix looses its shine, the matrix should be placed on to the prepared tooth, \& held undisturbed till the initial polymerization.

Fabrication of provisional restoration for post $\&$ core treated tooth ${ }^{2,3}$ (Fig.6-9)

- After the radicular preparation of the tooth, if adequate coronal structure is present, the retention for provisional restoration is obtained by both coronal and radicular part.

-If the remaining is very short, the retention is entirely depends upon radicular extension.

-Fabrication of provisional restoration by using orthodontic wire or endodontic file by both direct and indirect technique.

\section{Interim post preparation}
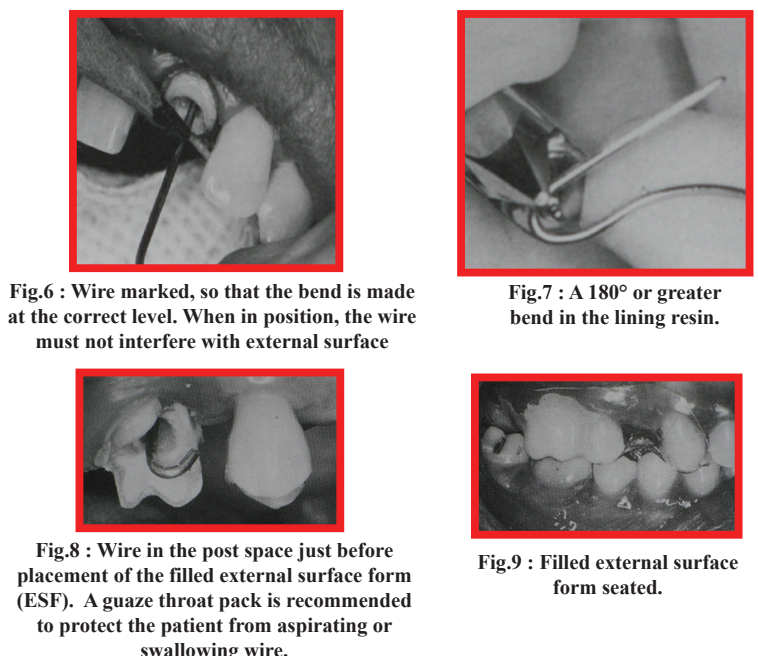

Fig.9 : Filled external surface form seated. 


\section{Fabrication of provisional restoration for porcelain laminates ${ }^{5}$}

-After tooth preparation, impression is made \& cast is fabricated.

-The preparation is covered by petroleum jelly, the composite resin of appropriate shade is placed on it properly contoured and light cured.

-The composite laminate is recovered \& petroleum is cleaned.

-Three areas of about $1 \mathrm{~mm}^{2}$ are etched on the prepared tooth \& bonding agent is applied only in that areas and laminate is pressed against the tooth and cured for 20 secs.

\section{Indirect technique for multiple laminates ${ }^{5}$}

-The diagnostic wax up is done on the cast and matrix is fabricated. After tooth preparation impression is made and cast is poured.

-The matrix is utilized to fabricate the provisional restoration by indirect technique.

\section{Provisional restoration for adhesive bridges ${ }^{3}$}

-The diagnostic wax up for the adhesive bridges is made and the matrix is prepared after the tooth preparation.

-The pontic is placed and is connected to adjacent retainers by small amount of light curing resin.

Provisional restoration for pin ledge restorations

-After the tooth preparation the prepared grooves are protected by placing the plastic pins and the auto polymerizing resin is added by brush bead technique and thus the provisional restorations are fabricated.

\section{Provisional restoration for severely fractured anterior tooth}

-The severely fractured teeth are indicated for endodontic treatment or pin retained restorations till the completion of the endodontic treatment and fabrication of the definitive prosthesis the provisional restorations are indicated.

-The impression is made \& obtained cast is utilized for matrix formation.
Provisional restoration for the abutment tooth of the R.P.D

-In some clinical conditions the existing removable partial dentures have to be restored by complete coverage crowns.

-The provisional crown is fabricated by indirect which is under contoured. The crown is placed on the abutment tooth and the self curing resin is mixed \& placed at the occlusal rest area $\&$ retentive terminal area.

-The C.P.D is inserted into the oral cavity \& removed several times to mould the self curing resin. Once the resin reaches the rubbery stage the crown is removed \& polymerized in hot water or pressure pot.

\section{Provisional restorations for optimizing esthetics in anterior maxillary implants ${ }^{7,8}$}

-Two provisional abutments were fitted on the implant analogs and modified according to the desired restoration contour with silicon keys from the wax up.

-In order to improve the esthetic appearance \& minimize plaque accumulation, the labial side of the restoration was formed by using veneers from acrylic denture teeth.

-The veneers were attached on a silicon index from the wax up and the restoration was completed with heat polymerizing acrylic resin.

-The use of acrylic veneers for the construction of provisional restoration is definitely a technique sensitive \& time consuming procedure, but improved esthetic performance can be thus achieved, compared with the use of only heat polymerizing acrylic resin.

\section{Provisionals for ITI solid abutments ${ }^{9}$}

This article describes several methods for the direct intraoral fabrications of provisional restorations for the ITI solid abutment.

1.Burn out coping technique

2.Resin coping technique

3.Impression cap technique

4.Protective cap technique 


\section{Polycarbonate Crown Form Technique $e^{1,2,3,8}$}

Pre-fabricated polycarbonate crowns are easily adapted to produce esthetic provisional crowns in an expeditious manner on prepared single anterior tooth in most patients

\begin{tabular}{|l|l|}
\hline Table 2. Steps using Polycarbonate Crown Forms \\
\hline 1. & $\begin{array}{l}\text { Select the crown form with the best fit. The fit will probably not be perfect, but it can be adjusted. } \\
\text { The width of the adjacent teeth is important when selecting the polycarbonate form. If the length is } \\
\text { long, trim the margins down by utilizing an acryic bur or crown and collar scissors. Do not trim the } \\
\text { incisal edge to correct the length. Keep trying the form on the tooth after each trimming untli the } \\
\text { length and width are approximately the correct size. }\end{array}$ \\
\hline 2. & $\begin{array}{l}\text { Open the contact areas. Make a V-shaped cut into the mesial and distal contacts by utilizing a } \\
\text { pointed acrylic bur. Make this opening approximately } 3 / 4 \\
\text { allows of the way down the contact area. This }\end{array}$ \\
\hline 3. & Coat the tooth with a separating medium. \\
\hline 4. & $\begin{array}{l}\text { Mix the acrylic material until it is homogenous and then pour the acrylic into the crown form. } \\
\text { Placing your fingers on the mesial and distal walls will help form the acrylic until the shell is placed } \\
\text { on the tooth. }\end{array}$ \\
\hline 5. & Insert crown on prepared tooth once the acrylic loses its shine. \\
\hline 6. & $\begin{array}{l}\text { When the material starts to set, gently remove and replace the crown form from the tooth in } \\
\text { approximately } 10-\text {-second intervals, unti it reaches final set. This should be done for approximately } \\
2 \text { to } 3 \text { minutes until material is set. }\end{array}$ \\
\hline 7. & Remove the crown. \\
\hline 8. & Trim accordingly. \\
\hline
\end{tabular}

\section{Alginate Paint Thin Shell Technique $e^{1,2,3,8}$}

This technique utilizes an alginate impression prior to the tooth preparation. If you cannot obtain an impression, you cannot use this technique. This technique can save chair time because the restoration is partially fabricated prior to preparation appointment.

\section{Table 3. Steps using alginate paint thin shell technique}

1. Prior to tooth reduction, prepare the tooth by adding wax to fill in any missing tooth structure. Take an accurate siginate impression, preferably with a triple tray to accurately reproduce the occlusion. Wrap impression in a moist paper towel of store in a humidor until ready to use

2. Utilizing two dappen dishes or a triple dappen dish, place acrylic monomer in one and polymer in the other.

3. Use a paint brush to transfer the acrylic material to the impression.

4. Paint the acrylic into the impression untl the buccallingual or facial/abial walls are covered. If the material is too thick, use a little monomer on the brush to thin out what was placed in the impression. The contact areas should not be included.

5. Once the material is set, use a pointed instrument to remove the shell from the impression. 6. If upon removal you notice any voids, paint a small amount of acrylic over the discrepancies. 7. It may be necessary to hollow out the inside. This can be done using a \#8 round bur.

8. Use this shell to make your provisional by relining with acrylic.

9. Place on tooth and have patient bite into place.

10. Carefully place and remove until set

11. Trim accordingly.

\section{Free-hand (Block) Technique ${ }^{8}$}

Recommended for experienced dentists.No matrices or impressions are used with this technique. It allows for good marginal adaptation and proper occlusion.

Table 4 - Steps using free hand technique

1. Lubricate prepared tooth

2. Mix a thick viscosity of acrylic.

3. When the acrylic has lost its luster, place an appropriate amount of material (about the size of the tooth or teeth that are prepared) on top of the tooth or teeth and form.

4. Form the acrylic buccally and lingually to the adjacent teeth and have the patient bite down to establish occlusal height.

5nce the material has started to get firm and before final set, place and remove from preparation to prevent provisional from locking in undercuts or on tooth.

6. Before final set, place a very thin $\mathrm{m}$ (x (pouring consistency) of acrylic inside the crown and place back on the tooth. This will give you a more definite margin and reduce the need for touch-up with a brush later.

7. Once final set is achieved, trim and finish.

\section{Preformed Anatomic Metal Crown Technique ${ }^{2,8}$}

Aluminum, gold anodized and stainless steel crown forms all fall into this category. They can be used by themselves, relined with acrylic or a combination of both. These crown forms cannot be utilized for multiple units. The gold anodized forms seem to work the best for this technique because of the softness of the material.

Table 5- Steps using preformed metal crown

1. Select the most appropriate size form.

2. Check occlusal height. If the height is too high, utlilize crown and collar scissors to trim the gingival margin.

3. Cut a $\mathrm{U}$ out of both the mesial and distal contacts only if there is an adjacent tooth. If no adjacent tooth, cut slit on proximal surtace.

4. Gently pull the buccal and lingual walls open.

5. Mix the acrylic and place into preformed crown.

6. When the acrylic has lost its shine insert on the lubricated prepared tooth in the mouth or on a model.

7. When material starts setting, gently remove and insert the crown on the tooth until the acrylic has set, approximately 2 to 3 minutes.

8. Trim the flash

9. Remove the metal crown form with the crown and collar scissors.

10. Refer to trimming section to finish

\section{Wax Technique ${ }^{8}$}

Used to fabricate all single unit provisionals. No crown forms or alginate impressions are necessary, so fairly inexpensive.

Table 6: steps using wax technique

1. Warm up a piece of baseplate wax and place over unprepared tooth

2. Trim and save the wax impression.

3. After preparation, dispense material and fill the wax impression,

4. Place on prepared tooth.

5. Follow steps 3 through 8 as in the polycarbonate technique to complete.

\section{Aluminum Shell Technique ${ }^{2,8}$}

\begin{tabular}{|c|c|}
\hline & $\begin{array}{l}\text { Once you have found the appropriate size, try it on the tooth to make sure the distance between } \\
\text { contacts is correct. }\end{array}$ \\
\hline 2. & $\begin{array}{l}\text { See how much is necessary to trim at the gingiva. If the crown is } 2 \mathrm{~mm} \text { above the adjacent teeth, } \\
\text { then you would trim } 2 \mathrm{~mm} \text { all around at the gingiva using a crown scissors. It is important to trim in } \\
\text { a smooth manner so as not to leave sharp or uneven edges that can irritate the gingiva. }\end{array}$ \\
\hline 3. & $\begin{array}{l}\text { Use contouring pliers to crimp the margins of the crown inward (Contouring pliers Nos, } 112,114 \\
\text { and } 115 \text { are most common.) Using the contouring pliers helps in adapting the crown to the finish } \\
\text { line. It is possible to omilt the contouring and reline the shell with methylmethacrylate (seif curing } \\
\text { acrylic). This will give you a better internal fit and more exact margins and is probably preferable } \\
\text { since it helps avoid a metal overhang. }\end{array}$ \\
\hline 4. & $\begin{array}{l}\text { Once the crown is seated on the prepared tooth, insiruct the patient to bite down normally. This } \\
\text { helps establish an initial occlusal anatomy onto the soft aluminum shell. }\end{array}$ \\
\hline 5. 1 & Further check the occlusion with articulating paper and make adjustments. \\
\hline & $\begin{array}{l}\text { Check crown for rough metal margins. These can be smoothed using sandp. } \\
\text { rubber wheel. }\end{array}$ \\
\hline
\end{tabular}

\section{Pre-fabricated Light-cured Composite Crown} Technique ${ }^{1,2,8}$

These crowns are malleable, light cured, preformed, and are available in a variety of shapes and sizes. They are a simple and esthetic solution for posterior provisionals. These types of tooth-colored pre-fabricated crowns can be quickly adjusted prior to light curing. 
With no impression or matrix needed, fabrication is quick and relatively easy. Start with the smaller size crown, as it can easily be contoured to modify to a slightly larger size. Trim the crown short, rather that leaving it too long. The tack cure should be no longer than 2-3seconds per surface.

\begin{tabular}{|c|l|}
\hline Table 8. Steps Using Pre-fabricated Light-cured Composite Crown \\
\hline 1. & Measure mesial to distal width to determines width of provisional. \\
\hline 2. & Select the appropriate size according to the manufacturer's chart. \\
\hline 3. & Open unidose container and remove from the protective plastic covering. \\
\hline 4. & Using crown and bridge scissors, trim following gingival contour of the tooth. \\
\hline 5. & $\begin{array}{l}\text { Seat trimmed crown gently on the preparation. Using your gloved fingers, ensure that the crown is } \\
\text { in line with the teeth. Establish interproximal contacts and margins. }\end{array}$ \\
\hline 6. & Have the patient gently close to establish occlusion. \\
\hline 7. & $\begin{array}{l}\text { Once the provisional is correctly adapted and adjusted, tack cure the provisional crown with a } \\
\text { curing light - while in the patient's mouth - for } 3 \text { seconds on buccalliablal, occlusal and lingual. }\end{array}$ \\
\hline 8. & $\begin{array}{l}\text { After tack cure, remove crown, then carefully put the crown back in place a couple of times to } \\
\text { ensure fit before the final cure. }\end{array}$ \\
\hline 9. & Final cure for 60 seconds, per manufacturer's directions. \\
\hline 10. & Finish and polish \\
\hline
\end{tabular}

\section{Acrylic Preliminary Impression Technique $e^{1,2,8}$}

This procedure requires an accurate impression prior to and after the tooth preparation. If the tooth is broken down, or a bridge is being constructed to replace a missing tooth, this technique may not be effective without adding wax to those areas.

Always remember to place the provisional on and off during setting to prevent locking provisional on the tooth.

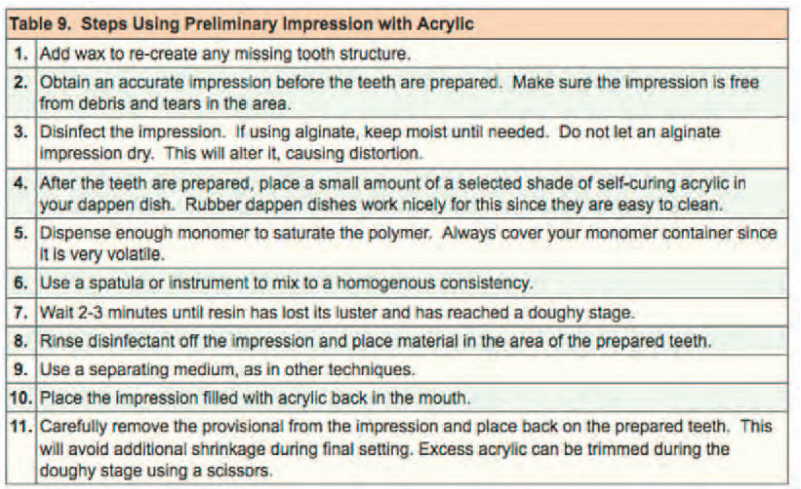

\section{Composite Resin Preliminary Impression Technique}

This procedure requires an accurate impression prior to and after the tooth preparation. If the tooth is broken down, or a bridge is being constructed to replace a missing tooth, this technique may not be effective without adding wax to those areas. Select the provisional material that is the closest to the natural tooth color. You can adjust the color by mixing colors or by adding a veneer of flowable composite to the exterior of the provisional after adjusting.

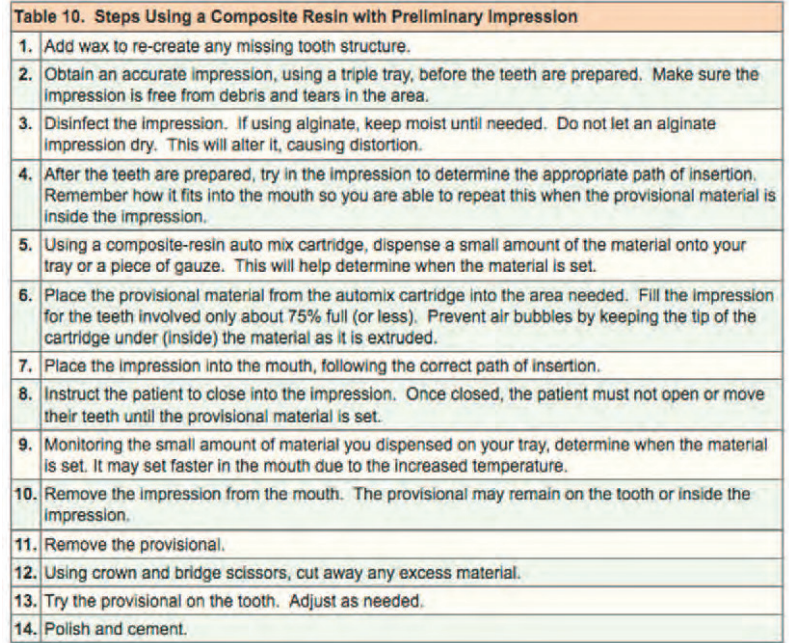

\section{Vacuum Form Acetate Shell Technique ${ }^{3,8}$}

This procedure utilizes the vacuum forming machine. It allows you to duplicate existing teeth prior to preparation. However, it also duplicates broken or missing portions of the teeth. Therefore, after the alginate is taken and poured, you should repair any existing discrepancies prior to using the vacuum former. If a tooth is missing, there are many ways to fill the space prior to making your template. They include: use of an acrylic tooth (denture tooth), use of a mix of acrylic formed using opposing model to establish occlusion, and the use of light-cured resin to form a tooth.

\section{The clear matrix has the following advantages:}

-Allows easy access and visibility throughoutthe procedure.

- Can serve as a tooth preparation/reductionguide.

-Provides a smooth, void-free surface that gives a better finish to the surface of the provisional.

-Can be used with self- or light-cured materials. -Is inexpensive to produce.

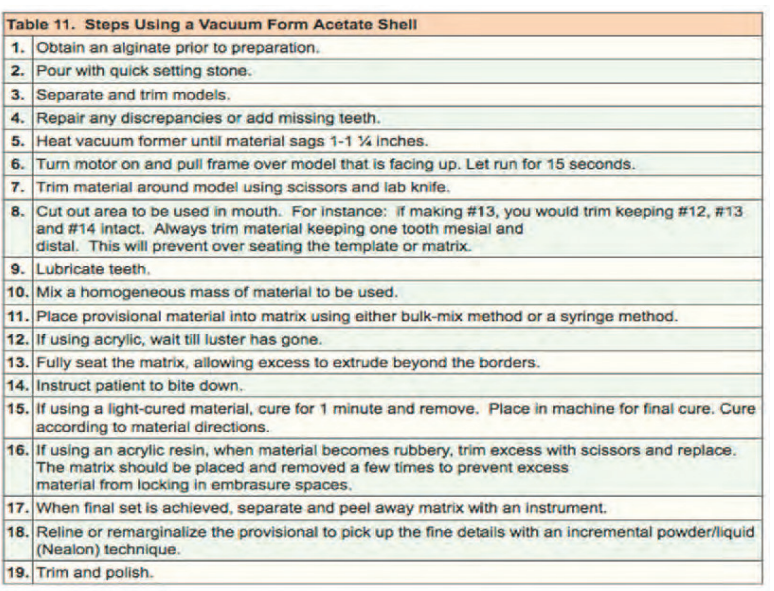




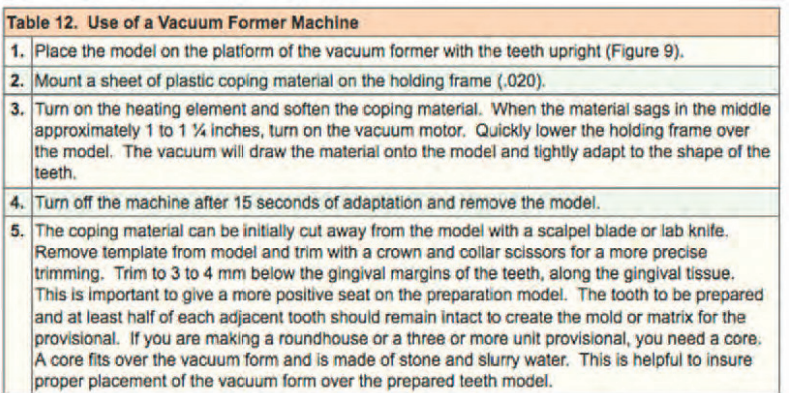

\section{Reline Previous Crown Technique}

An existing crown can be used as a provisional if it remains intact upon removal and is smooth and aesthetically pleasing. When a crown is removed or remade, keep in mind the reasons for replacement. If it is for esthetics, you would want to make a new provisional. If it is because of poor fit, you can reline with acrylic to serve as a provisional. In most cases, it is best to make a new well-fitting provisional.

\section{Celluloid Crown Form Technique}

A celluloid crown form can be used to fabricate a single unit provisional. It is extremely helpful when using light-cured materials because the material can be cured through the clear form.

\section{Inlay and Onlay Provisional Technique}

An inlay and onlay should be fabricated by a proficient assistant. The small size and intricate margins require precise fabrication and trimming. This technique closely relates to the freehand technique discussed earlier. The only difference with this technique is that the whole clinical crown is not covered.

\section{Provisional Over Implant Technique}

To fabricate a provisional over an implant, the assistant must be familiar with implants and their coordinating parts. Indirect technique is recommended.

\section{Long-term Provisional Technique}

Provisional crowns may have to be fabricated to last several months. In such instances, metal bars or a mesh material may be used to help provide durability. For an anterior provisional, the material should be placed on the lingual surface; for posterior teeth, the material should be placed on the occlusal surface. Placing mesh prior to pouring material can be very difficult. The mesh may move during the pouring process and be in the wrong position while final set occurs. For the inexperienced, it is easier to cut a long groove in the occlusal Or lingual surface. Then place the bar or mesh and cover with material. Before placing the material over a metal bar reinforcement, make sure the bar will not interfere with the patient's occlusion.

\section{Limitations $\mathbf{s}^{1,2}$ :}

1.Lack of inherent strength

2.Poor marginal adaptation

3. Colour stability

4.Poor wear properties

5.Inadequate bonding characteristics

6. Time expenditure for fabrication can be prohibitive.

\section{Conclusion}

The utilization of proper provisional prosthodontic appliance will permit a higher rate of success of the treatment. This phase of restorative treatment should not be merely considered a temporary but as a template for the ensuing prosthesis. The information that is obtained in this phase of treatment will reduce the problems that may be encountered in the definitive treatment.

\section{References}

1. Rosenstiel SF, Land MF, Fujimoto J. Contemp Fixed prosthodont. 4th ed. .p.466-505.

2. Shillinburg HT, Hobo S, Whitsett LD, Jacobi R, Brackett SE. Fundamental of fixed prosthodontics. 4th ed. .p.225-253.

3. Tylmann. Theory and practice of crown \& bridge prosthodontics. 8th ed. .p.255-272.

4. Donovan TE, Cho GC. Diagnostic provisional restorations. J Esthet Dent 2000;12:238-247.

5. Laminate veneer provisional restoration. J Prosthet Dent 1997;77:109-110.

6. Netti CA, Yard RA. Temporization of abutment teeth preparations for existing removable partial denture- J Prosthet Dent 1989;62:428-430.

7. S. Kowitis, Psarri C. Provisional restorations for optimizing esthetics in anterior maxillary implants- J Esthet Restor Dent 19:6-17, 2007. 
8. Cleveland CM, Allen AD, Henson N. Fabrication of provisional crowns and bridges. Dent Clin North Am 1987;31:3.

9. Dunbrigue HB, Esquivel JF, Grun DC. Options for the fabrication for provisional restorations for ITI solid abutments. J Prosthet Dent 2001;428-430.

\section{How to cite this article:}

Praveen B, Prasanna B.G, Harsha S, Chandana N. Techniques for Interim Rrestorations in

Fixed Partial Denture Prosthesis - A Review. CODS J Dent 2015;7: 76-83.

Source of support: Nil. Conflict of interest: None Declared. 